\title{
Caravana Farkas: uma experiência brasileira
}

\section{Marcius Freire}

\section{Resumo:}

Este artigo pretende lançar um olhar para os filmes que fizeram parte da Caravana Farkas procurando suas homologias com os cinemas direto e verdade. Serão buscados os traços distintivos desses filmes em relação à história do documentário brasileiro, considerando que tanto o cinema direto quanto o cinema verdade nascem quase que simultaneamente na França, nos Estados Unidos e no Canadá em torno de nomes como Jean Rouch; os irmãos Maysles, Leacock e Pennebaker; e Michel Brault, respectivamente. Dessa forma, serão levantados pontos de aproximação e distanciamento quanto às possibilidades de tratar os filmes da Caravana Farkas como participantes, no Brasil, desses movimentos.

\section{Palavras Chave:}

Caravana Farkas, documentário, cinema verdade, cinema direto, cinema brasileiro.

\begin{abstract}
:
The present article intends to set light on the movies that were part of the so called Caravana Farkas (Farkas Caravan), searching them for a set of homologies with the direct and vérite cinemas. We have focus on identifying the distinguishing aspects of such movies taking in the whole of Brazilian documentary history, since both direct cinema and vérité cinema were born almost simultaneously in France, in the United States and in Canada related to the names of Jean Rouch; Maysles brothers, Leacock e Pennebaker; and Michel Brault, respectively. From this perspective, then, we consider the moments that approximate or distance us from possibly considering the Caravana Farkas movies as belonging to such movements in Brazil.
\end{abstract}

\section{Keywords:}

Caravana Farkas, documentary, cinéma verité, direct cinema, Brazilian cinema.

Este texto tem sua origem em uma comunicação que fizemos no quadro da V Conferência Internacional do Documentário (1), cujo tema geral era "Cinema direto e cinema verdade: tendências e dispositivos do documentário na era digital". A mesa redonda de que participamos se intitulava "Caravana Farkas: uma experiência brasileira". Assim como aconteceu na apresentação do evento, devo confessar que, ao propor este artigo, fiquei a me perguntar por onde começar. "Caravana Farkas: uma experiência brasileira". Sim, uma experiência bem conhecida de quem já se debruçou sobre a história do documentário nacional. Mas, o exame dessa experiência deveria - pelo menos foi o que imaginei - ser efetivado a partir da temática mais ampla em que estava inserido.

Evidentemente, parece-me de difícil execução um qualquer exercício de simulação de viagem no tempo que me levasse a imaginar o que teria sido a experiência da Caravana se existissem, então, os dispositivos que caracterizam a nossa "era digital". Resta, portanto, como alternativa a uma certa fidelidade ao tema acima proposto, eliminar a segunda parte do título atendo-me à primeira. Ou seja, abrigar a "Caravana" mais nos cinemas direto e verdade, e menos nas tendências e dispositivos do documentário na era digital. 
Assim, buscarei lançar um olhar para os filmes que fizeram parte da Caravana, procurando suas homologias com os cinemas direto e verdade. Tal procedimento servirá de álibi para algumas digressões sobre os traços distintivos desses filmes. Tanto o cinema direto quanto o cinema verdade nascem quase que simultaneamente na França, nos Estados Unidos e no Canadá em torno de nomes como Jean Rouch, na França; os irmãos Maysles, Leacock e Pennebaker, nos Estados Unidos; e Michel Brault, um pouco mais tarde, no Canadá.

Num primeiro momento, notadamente nos Estados Unidos, havia um certo clima de "movimento" que, se não gerou um "manifesto", deu origem a declarações de grande efeito, como a de Robert Drew, que chegou mesmo a afirmar que "a personalidade do cineasta não estava de forma alguma envolvida na direção da ação filmada" (2). Ou seja, havia praticamente a convicção de que o material filmado correspondia exatamente àquilo que tinha sido observado. Diga-se de passagem que o termo "observar" estava muito em voga naquele período. Richard Leacock, falando de seu filme Happy mother's day declara: "Nós nunca pedimos a ninguém para fazer o que quer que seja; nós éramos simplesmente observadores" (3). Já os irmãos Maysles afirmavam, falando de seus filmes: "É a vida observada pela câmera ao invés de - como é o caso da maioria dos documentários - a vida recriada para isso" (4).

Quer dizer, em razão da facilidade de poder passar - pelo menos em tese - despercebido por causa dos equipamentos leves de que se serviam e, assim, interferir minimamente no desenrolar das ações filmadas, muitos chamaram esse tipo de cinema de "não intervencionista" - alguns cineastas, como vimos, foram levados a acreditar que o resultado de seu trabalho era despojado de qualquer traço de subjetividade. Começaria então o exercício a que me referi acima citando a distinção que faz Erick Barnow, em seu livro Documentary. The History of the Non-Fiction Film, entre cinema direto e cinema verdade. Tal distinção é bastante precisa ao traçar as grandes linhas que demarcariam as fronteiras entre os dois movimentos. Diz ele:

Os documentaristas do direto levavam sua câmera para uma situação de tensão e esperavam com otimismo por uma crise; a versão de Jean Rouch do cinema verité tentava precipitar uma crise. O artista do cinema direto almejava a invisibilidade; o artista do cinema verdade de Rouch era, no mais das vezes, um participante declarado. O cineasta do direto representava o papel de um espectador descompromissado; o artista do cinema verdade adotava o comportamento de um provocador (BARNOW, 1993: 254-255).

Diante dessa definição comparativa, que corresponde de forma bastante fiel àquilo que vinha a ser uma e outra formas documentais, é lícito nos perguntarmos em que os filmes da Caravana com elas se identificam, e em seguida, nos perguntarmos: por que essas produções são consideradas como parte da história do Cinema Verdade e/ou do Cinema Direto no Brasil?

À primeira vista, me custa sustentar que realizadores como Paulo Gil Soares, de Vaquejada, como Geraldo Sarno, de Casa de Farinha, ou o próprio Sérgio Muniz, de O rastejador, tenham levado seu equipamento para o sertão nordestino e esperado por um qualquer acidente digno de ser registrado e, menos ainda, que tenham tentado passar despercebidos de seus sujeitos, como uma mosca da parede que vê sem ser vista, a exemplo do que pretenderam fazer Robert Drew, Richard Leacock, D. A. Pennebaker em filmes como Crises: Behind a presidential commitment, de 1963; D. A. Pennebaker em Don't look back; ou, ainda, Richard Leacock em Happy mother's day. Tampouco parece-nos plausível inferir, a partir das imagens e sons com os quais nos deparamos, que A morte do boi, Vaquejada ou Vitalino/Lampião sejam resultado de uma qualquer crise precipitada por Paulo Gil Soares ou Geraldo Sarno. Menos ainda que esses cineastas tenham sido, nessa série de filmes, "participantes declarados" ou 
que tenham adotado o comportamento de "provocadores".

Indo além das tentativas de demarcação de fronteiras entre os dois movimentos, Stephen Mamber, em seu livro Cinema Verité in America, e procurando defini-los a partir de uma mesma matriz, afirma que "o elemento essencial no cinema verdade é o ato de filmar pessoas em situações fora de controle". Por "fora de controle" - diz ele - "queremos dizer que o documentarista não funciona como um 'diretor', tampouco como um roteirista". E prossegue:

Em um filme de cinema verdade, a ninguém é dito o que dizer ou como atuar. Um roteiro preparado, mesmo que de forma rudimentar, não é permitido, tampouco o são sugestões verbais, gestos, ou qualquer forma de comunicação direta do documentarista para seu sujeito. O cineasta não deve, de maneira alguma, indicar que uma ação é preferida por ele em detrimento de qualquer outra. O cineasta atua como um observador, tentando não alterar as situações que testemunha de qualquer outra forma que não seja simplesmente pelo fato de estar lá (no mais das vezes com outra pessoa que grava o som). O cinema verdade acredita na espontaneidade; a má vontade em impor qualquer tipo de controle vai tão longe quanto recusar a recriação de eventos, fazer as pessoas repetirem ações apenas porque estão sendo filmadas. As entrevistas tampouco são empregadas, uma vez que o seu uso, na realidade, é uma forma de dirigir o comportamento (MAMBER, 1974: 2).

Por fim e para ficar por aqui com as tentativas de definição dos traços distintivos dos cinemas direto e/ou verdade, gostaria de me referir ao crítico René Prédal em seu artigo "Rouch d'hier à demain", publicado no número especial da revista Cinémaction dedicado ao antropólogo-cineasta, intitulado Rouch ou le ciné-plaisir. Prédal aponta alguns detalhes que, segundo ele

(...) irritavam os adversários do cinema "verdade": o "direto" freqüentemente evitava, por exemplo, a música, elemento geralmente "enobrecedor" (sobretudo se ela é clássica) da matéria fílmica. Da mesma forma, os diálogos não são escritos, o que confirma o lastimável desaparecimento dos auxiliares literários que dão ao cinema ses lettres de noblesse, suas "credenciais nobres": os textos são artísticos, pelos sons, pelas palavras ou pelas imagens. Em suma, muitos cinéfilos não reconhecem, de maneira mais ou menos inconsciente, a qualidade de arte do cinema a partir do momento em que este filma ele próprio a arte, quer dizer, olha de soslaio em direção à literatura, à pintura ou à música. Mas se ele olha somente o real, perde seu status artístico a não ser no caso em que testemunha com ostentação um trabalho onipresente sob a forma, se ele compensa sua essência "natural" com uma mise en forme, uma construção destinada a mascarar suas origens (PREDAL, 1996: 16).

Assim, temos mais algumas características das realizações direto/verdade: a) inexistência de roteiro, mesmo que rudimentar. Ora, todos os filmes da Caravana têm um roteirista em seus créditos; b) inexistência de sugestões verbais, gestos, ou qualquer forma de comunicação direta do documentarista para seu sujeito. Parece bastante plausível inferir que filmes como Viva Cariri, de Geraldo Sarno, ou Erva bruxa, de Paulo Gil Soares, têm, em muitas sequiências, a auto-mise en scène dos sujeitos filmados construída a partir de instruções vindas de fora do campo; c) recusa da recriação de eventos. Ao que parece, todas as atividades do agente de $\mathrm{O}$ rastejador foram recriadas para a câmera; d) eliminação das entrevistas. Elas estão presentes em praticamente todos os filmes: Em Viva Cariri, o entrevistador, fora de campo, pergunta sobre o tempo de maturação da mandioca. Frei Damião, de Paulo Gil Soares, é todo ele baseado na entrevista a Frei Damião; e) a ausência de música extra-diegética. Ora, ela está presente em praticamente todos os filmes. Em A erva bruxa, de Paulo Gil Soares, temos um concerto de Vivaldi acompanhando a apresentação dos créditos; em $O$ engenho, de Geraldo Sarno, temos melodias executadas por flauta e piano; e em Os imaginários, do mesmo Geraldo Sarno, a "Missa Criolla", de Ariel Ramirez, 
acompanha a fabricação de bonecos de madeira.

A partir de tudo que precede é lícito nos perguntarmos as razões que levaram muitos críticos e historiadores do cinema documentário brasileiro a indexar (para usar esse conceito de Noël Carrol) esses filmes como cinema direto/verdade. Será que não seria pura e simplesmente porque eles fazem uso do som direto? Sem buscar categoricamente possíveis respostas, gostaria, no entanto, de lançar uma hipótese que vou tentar demonstrar em rápidas palavras.

É sabido que os filmes da Caravana foram realizados com vistas à sua possível comercialização (venda ou aluguel) junto a escolas. Tratava-se, portanto, de realizar filmes que pudessem mostrar aos nossos jovens de então aspectos da realidade do seu país. Se a primeira região escolhida foi o nordeste, sabemos que a idéia era cobrir todas as regiões do Brasil. Há, portanto, por parte da equipe, uma declarada intenção de informar, de conhecer e dar a conhecer traços intrínsecos à nossa cultura, às nossas tradições, e transmitir, em seguida, esses conhecimentos a espectadores muito especiais, espectadores que se encontram na condição de recebedores - para não dizer "consumidores" - de conhecimento que são os alunos de uma escola. Nesse sentido, vemos com dificuldade filmes documentários calcados nos preceitos do direto/verdade, preceitos esses que vimos acima, cumprirem esse papel.

É por essa razão, talvez, que são encontrados nesses filmes resquícios do modelo griersoniano, notadamente no papel assertivo da narração, pois é esta que indica e pontua a presença dos outros elementos constituintes da diegese fílmica. A organização desses elementos se dá em função de uma "construção dramática" que vai produzir o sentido desejado pelo autor. E esse sentido se quer portador de conhecimentos que devem ser transmitidos aos espectadores, daí o caráter "didático" que os subtendem. Tal caráter didático toma forma não pelas características do comentário, como muitos seriam inclinados a pensar, mas pelo relacionamento interno das diversas instâncias narrativas que entram em jogo na construção dos filmes e sobre as quais voltaremos a seguir.

A outra vertente dessas produções que eu gostaria de explorar rapidamente é aquela que os identifica, de forma inequívoca, com a etnografia ou, melhor dizendo, com a etnocinematografia. Com efeito, é fácil verificar que praticamente todos esses filmes têm como ponto de partida, como mote, uma manifestação cultural qualquer própria da região nordeste. No mais das vezes, essa manifestação, seja ela uma técnica material, um ritual ou uma técnica do corpo (utilizando aqui o conceito de "técnica do corpo" de Marcel Mauss), serve de fio condutor através do qual o diretor faz o espectador penetrar no universo socioeconômico de seus sujeitos. Enquanto as imagens cumprem, quase sempre, o papel de descrever essas atividades de maneira bastante precisa, o comentário contextualiza o trabalho executado através de um discurso de fatura griersoniana. Seja em Vaquejada, em A morte do boi, em Vitalino/Lampião. O "jogo" que consiste em derrubar bois puxando-os pela cauda, no primeiro caso, o sistema primitivo de abate do gado no segundo e a confecção dos famosos bonequinhos de barro do mestre Vitalino são atividades descritas de forma minuciosa pelas imagens.

E o que é a descrição em antropologia? Segundo François Laplantine, em seu livro La description ethnographique, a descrição etnográfica (que significa a escrita das culturas), sem a qual não existe antropologia no sentido contemporâneo do termo, não consiste somente em ver, mais em dar a ver, quer dizer, escrever aquilo que se vê:

A descrição, que é tanto exploração do vocabulário quanto do fenômeno propriamente dito do qual procuramos prestar contas, parece ser da ordem da enumeração. A descrição enuncia e anuncia, enumera, soletra, detalha, decompõe, mas primeiramente registra, demonstra, recenseia, contabiliza. Não se trata de uma atividade particularmente imaginativa: ela constrói listas, estabelece o estado dos lugares, produz inventários (LAPLANTINE, 1996: 29). 
Essa definição parece ir ao encontro de Roger Bastide quando este afirma que "no trabalho de campo o etnólogo não deve se contentar em fazer as pessoas falarem; ele tem de aprender a fazer com que as coisas falem e a escutá-las" (BASTIDE apud BALFET, 1983: 44). E o que são as atividades acima enumeradas por Laplantine senão a resposta que as coisas do mundo histórico apresentam ao pesquisador em reação às suas inquirições? Ambos, Laplantine e Bastide, nada mais fazem do que confirmar a assertiva de Michel Foucault ao analisar as relações entre o discurso e o visível: "Nós estamos convencidos, nós sabemos que em uma cultura tudo fala: as estruturas da linguagem dão forma à ordem das coisas" (FOUCAULT, 2001: 649).

Mas Laplantine vai buscar em Gerard Genette um outro papel à descrição no interior na narração:

A descrição entra em conflito permanente com a narração, cujo movimento ela interrompe. Enquanto esta última é dinâmica, tempo, movimento, desenvolvimento de uma intriga no seio da qual personagens evoluem, a descrição demora, produz paradas na imagem, concentra sua atenção em um dado momento, em um lugar preciso, em um episódio decisivo. A descrição é, como diria Gerard Genette, uma "pausa na narração” (LAPLANTINE, 1996: 31).

Ora, retomemos o último filme citado, ou seja, Vitalino/Lampião como exemplo de um filme etnográfico e voltemos às instâncias narrativas a que nos referimos antes. É fácil verificar que várias dessas instâncias nele estão presentes. A instância imagética descreve, com riqueza de detalhes, a transformação de uma matéria, o barro, em bonecos representativos da cultura local. A narração informa sobre o papel simbólico das figuras representadas - no caso, Lampião - e a relação do artesão com elas; este tomado como um caso particular, mas que representa uma realidade de caráter geral. Enquanto a narração interpreta a relação do artesão com os personagens que cria, a trilha sonora é composta pela voz de um cantador cuja cantoria tem como tema as peripécias de Lampião.

Não há, portanto, no sentido estrito utilizado por Genette falando da linguagem escrita, uma "pausa na narração", uma vez que a narração é feita em voz over ou off e a descrição feita pelas imagens, enquanto a trilha sonora como que traz um elemento genuíno da cultura observada para caucionar, avalizar o que as duas outras instâncias apresentam. Temos, assim, três instâncias que interagem para criar aquilo que Thomas Farkas defendeu como seu modelo de documentário, aquele em que "as coisas são ditas não pelas pessoas entrevistadas, mas pela construção dramática do filmes".

Encerraria dizendo que a "construção dramática" desses filmes os identifica com aquilo que chamei de etnográfico/didático, retomando uma das categorias criadas nos idos de 1948 por André Leroi-Gourhan. Nesse sentido, eles não cumpriram o papel para o qual foram criados à época porque os espectadores a que se destinavam não tiveram acesso a eles; hoje, entretanto, constituem repositórios preciosos de elementos de nossa cultura que, certamente, já não mais existem, ou se transformaram ao longo do tempo. E isso só faz realçar seu caráter etnográfico.

\section{Bibliografia:}

BALFET, Hélène. “Technologie”. In: CRESSWELL, Robert (ed.). Eléments d'ethnologie générale. Paris: Armand Colin, 1983.

BARNOW, Erik. Documentary. A History of the Non-Fiction Film. Oxford/New York: Oxford University Press, 1993. 
BORDIEU, Pierre. Les règles de l'art. Genèse et structure du champ littéraire. Paris: Seuil, 1998.

CARROLL, Noël. "Nonfiction Film and Postmodernist Skepticism". In: BORDWELL, David \& CARROLL, Noël. Post-Theory. Reconstructing Film Studies. Madison: The University of Wisconsin Press, 1996.

COMOLLI, Jean-Louis. Voir et pouvoir. L'Innocence perdue: cinéma, télévision, fiction, documentaire. Paris: Éditions Verdier, 2004.

DEVEREAUX, Leslie. "Cultures, Disciplines, Cinemas". In: DEVEREAUX, Leslie \& HILLMAN, Roger (eds.). Fields of Vision. Essays in Film Studies, Visual Anthropology and Photography. Berkeley: University of California Press, 1995.

FOUCAULT, Michel. "Les mots et les images”. In: Dits et écrits. Vol. I (1954-1975). Paris: QuartoGallimard, 2001.

LAPLANTINE, François. La description ethnographique. Nathan: Paris, 1996.

PREDAL, René. “Rouch d'hier à demain”. In: CinémaAction, n 81, 4e trimestre, 1996.

RENOV, Michael. Theorizing Documentary. New York: Routledge, 1993.

WINSTON, Brian. "The Documentary Film as Scientific Inscription”. In: RENOV, Michael. Theorizing Documentary. New York: Routledge, 1993.

\section{Notas:}

(1) Conferência realizada em 2005.

(2) Cf. Winston, Brian. "The Documentary Film as Scientific Inscription". In: Renov, Michael. Theorizing Documentary. New York: Routledge, 1993, p.43.

(3) Idem, Ibidem, p.44.

(4) Idem, Ibidem, p.43.

\section{Mini Currículo :}

Professor livre docente no Departamento de Cinema e do Programa de Pós-Graduação em Multimeios da Unicamp. 